\title{
Post Disaster Reconstruction after 2015 Gorkha Earthquake: Challenges and Influencing Factors
}

\author{
Keshab Sharma ${ }^{1}$, Apil KC ${ }^{2}$, Mandip Subedi' ${ }^{2}$ Bigul Pokharel ${ }^{3}$ \\ ${ }^{1}$ Department of Civil and Environmental Engineering, University of Alberta, Edmonton, AB, Canada \\ ${ }^{2}$ Institute of Engineering, Central Campus, Tribhuvan University, Nepal \\ ${ }^{3}$ National College of Engineering, Tribhuvan University, Nepal \\ Corresponding author: keshab.sharma@gmail.com
}

Received: Feb 21, 2017 Revised: Oct 22, 2017 Accepted: Jan 1, 2018

\begin{abstract}
The Gorkha earthquake on April 25, 2015 has significantly affected the livelihood of people and overall economy in Nepal, causing severe damage and destruction in central Nepal including nation's capital. 800 thousand buildings were affected leaving 8 million people homeless. Challenge of reconstruction of optimum 800 thousand houses is arduous for Nepal Government in background of its turmoil political scenario and weak governance apart from its difficult geographical terrain. Albeit, with significant number of stakeholders involved in the reconstruction process, no appreciable progress has seen to the ground till date, which is reflected over the frustration of affected people. In order to identify factors hindering timely and quality reconstruction, this research has brought basic arguments and ideas prospected by different actors involved in the process. Methodology of the study is comprised with semi structured interviews with social mobilizers, engineers working in the field, and affected people, group discussion, field observations and regular follow-up of the incidents through national newspapers and discussion forums. This study concludes that inaccessibility, absence of local government, weak governance, weak infrastructures, lack of preparedness, knowledge gap and manpower shortage etc. are the key challenges of the reconstruction after 2015 earthquake in Nepal. Good governance, integrated information, addressing technical issues, public participation along with short term and long term strategies to tackle with technical issues are highlighted as some imperative factors for timely and quality reconstruction in context of Nepal.
\end{abstract}

Key Words: Gorkha earthquake, damage assessment, challenges, reconstruction, policy.

\section{Introduction}

Post-disaster reconstruction and rehabilitation is a complex process that involves the interaction of social, technological and economic factors. The 2015 Gorkha earthquake is one of the most devastated disasters in the modern history of Nepal. Hence, there is no comprehensive study on reconstruction after disasters in Nepal, which integrates the necessary information to deal with challenges and opportunities of reconstructions. Some researches after 2001 Gujarat and 2005 
Kashmir earthquake had mainly focused on post disaster mental health interventions, disaster relief problems and management inconsistencies, and healthcare challenges in disasters [2, 12]. However, most of these studies have not comprehensively evaluated the challenges of reconstruction after disasters, and more importantly, they have not used a qualitative approach to better understand the experiences and perceptions of disaster survivors. Thus, there is still a significant gap in this field. It is essential that academics, governments and humanitarian agencies learn from previous applications of this process in similar area in order to not only implement programme that reduce the current vulnerability but also to establish a legacy of disaster-risk reduction strategies.

This paper examines the challenges of reconstruction after 2015 Gorkha earthquake presenting the scale of devastation of the 2015 Gorkha earthquake and the research methodology in brief account. Field research involved observations, interviews and open ended questionnaires with affected people and other stakeholders. This research highlights a number of issues that would affect the reconstruction process in term of speed and quality. Based on the study, some recommendations are made in the conclusion section to speed up the reconstruction process in Nepal. The issues established through this paper are ones that need to be recognized by academics, governments and implementation agencies, and considered in the implementation of post-disaster reconstruction programme in the future specially in developing countries like Nepal.

\section{Scale of Devastation}

On April 25, 2015, Nepal was struck by a 7.8-magnitude earthquake, followed by a 7.3-magnitude earthquake on May 12, 2015, killing in total nearly 9,000 people and injuring 22,400. Also, more than 800,000 houses were damaged or destroyed $[8,14,15]$. Out of Nepal's 75 districts, 31 were deemed "most affected," and out of that number 14 districts were "severely affected" [16]. The government-led Post Disaster Needs Assessment (PDNA) estimates that Nepal's financial losses from the earthquake are US\$7.06 billion, which is 36 per cent of the country's GDP as of 2014 ${ }^{1}$. Different government and non-government sources also refer to estimated amount of 7 billion US Dollars required for the whole reconstruction process, with major focus of almost $49 \%$ required on the housing sector. Destruction is catastrophically widespread; residential and government buildings, heritage sites, schools and health facilities, rural roads, bridges, water supply systems, agricultural land, trekking routes and hydropower plants were all hit. The most heavily affected sector by far is social, which sustained about $61 \%$ of the destruction and subsequent decline in output, followed by productive sector at $17 \%$ whereas infrastructure sector and cross-cutting issues each suffered $10-12 \%$ of the total disaster effects $[13,16]$.

\section{Research Methodology}

Data were collected through semi-structured interviews, focus group discussions, and field notes. Engineers, officers, social mobilizers working under NRA and different International NonGovernment Organization (I/NGO) were selected randomly and interviewed from January 2016 to August 2016.

Some of the typical questions asked to engineers, officers and social mobilizers were as follow:

1. Why did it take more than 1 year to identify the earthquake victims?

2. Why you have not decided about relocation of the village located in vulnerable area?

3. Why only few thousand families have received the grant from government?

4. What do you want from government and local people to speed up the reconstruction

1 "Teaching Resources: Recovery to Reconstruction: Nepal after the 2015 Earthquakes" by Rufina K. Park, Asia Pacific Foundation of Canada 
process in your area?

5. What do you think is the biggest challenge to the reconstruction efforts in your working area?

Additionally, more than 100 local social workers, local party leaders and earthquake victims from Kathmandu, Dhading, Nuwakot, Sindhupalchowk, and Dolakha; some from most devastated districts during 2015 Gorkha earthquake; were interviewed with open-ended questions. Some of the typical questions asked to the earthquake victims were as follow:

1. Have you got any support from government after the earthquake?

2. Why you have not started to build your home yet?

3. What do you want to reconstruct your house within 3-6 months?

4. What are you expecting from NRA (or government)?

5. Do you know how safe is your place? Do you want to move from here to safer place?

6. Do you know about earthquake resistant house?

7. What do you think is the biggest challenge to the reconstruction efforts in your village and district (political transition, poverty, manpower, material, transportation, and other issues)?

As this study was based on interview and discussion, data analysis was based on qualitative content analysis principles. Number of crucial factors mentioned the stakeholders of the reconstruction were shortlisted and prioritized based on the emphasized given the stakeholders. Details of research methodology of this study can be found in Sharma et al. [16].

Post disaster reconstruction literatures in developing countries like Nepal were deeply reviewed where authors mainly focused on the researches of reconstruction process after 2001 Gujarat earthquake, 2003 Bam earthquake, 2004 Tsunami in Sri Lanka, 2004 Sumatra earthquake, 2005 Kashmir earthquake, and 2010 Haiti earthquake, having very similar building typologies, economic, political, geographical, and geological conditions with Nepal. Secondary data were collected from reports, action plans, and reflection papers of governmental entities, non-governmental organizations, private sector businesses, and the online news. Articles and field report published on national newspaper and magazine of Nepal were also reviewed to make some opinion for this paper.

\section{Results and Discussion}

\subsection{Summary of Literature Review}

This section is intended to summaries the lesson learnt from the reconstruction process in past from India, Sri Lanka, Indonesia, Pakistan, Iran and Haiti.

Top down relocation plan and construction of contractor driven mass housing without social consultation has resulted in numerous abandoned houses in Bhuj, Gujarat [1]. Lack of reconstruction framework in institution, policy and reliable data affecting housing targets and reconstruction plans has led to chaotic confusion and, ultimately, reconstruction delays in the reconstruction after 2004 Tsunami in Sri Lanka [18]. Lack of interface between community and the reconstruction authority, inaccessibility, lack of awareness, manpower shortage, and knowledge gap were pointed out as a key challenge of reconstruction in Pakistan after 2005 Kashmir earthquake [11]. Lack of coordination, commitment, policy and institutional framework had resulted conflict amongst the 
different stakeholder and led to duplication of works along with inefficient utilization of funds [17] after 2004 Sumatra earthquake and tsunami. Studies of post disaster construction works after 2003 Bam earthquake, Iran [3] concluded that inadequate funding and public participation are the key challenges in delaying the reconstruction works and resuming the normal life. Extent of the destruction, weak and dysfunctional government institution, complex urban landscape, lack of security, large number of aid actors involved and blanket military presence has been highlighted as the challenges of Haiti reconstruction [9].

\subsection{Results From Survey}

It is crucial for Nepal government to investigate the issues and challenges and find a concrete solution to overcome the complexity and uncertainties of post disaster reconstruction (PDR), so as to meet the target of build back better by 2020 . As the challenges of reconstruction are interlinked with different sectors and dimension, it is important to categorize into more common scope of studies. This section is intended to present the outcomes of the study and discuss in brief about the challenges and influencing factors for post disaster reconstruction in Nepal. As this study was based on open ended questions, group discussion and literature review, it is very difficult to quantify the results of the study in term of numeric value which evidently is the limitation of this study.

The study identified twenty main factors related to participants' main concerns, and experts' views. All these factors are interlinked to each other. However, it does not mean all the factors are equally challenges for all earthquake devastated areas. For an example, accessibility, loss of livelihood, negligence of local culture, and knowledge gap and building construction etc. are some crucial challenges for remote area whereas public participation, manpower shortage, rehabilitation and retrofitting and techno-legal regime are for urban area. Some other factors such as political transition, lacking local government, lack of coordination and bureaucratic burden etc. are equally critical for both remote and urban areas to speed up the reconstruction process. These main factors shortlisted from the survey are explained below:

\subsubsection{Political Transition}

Nepal is suffering from weak governance and corruption because of a decade long period of political transition. Various international agencies have reported that the nation has turned into fragile country with one of the lowest per capita income and HDI rank of 157 out of 187, with high level of poverty, social inequality and high corruption level with rank of $27^{\text {th }}$ in overall failed state index. Political instability, lawlessness, nepotism, clientelism, and lack of accountability prevail in the society and corruption is perceived to be a major concern [6]. As previous reconstruction experiences in developing countries like Nepal has also indicated, the politicization of the process has always been the foremost obstacle to the provision of timely, effective, and sustainable solutions. This is largely because the post-disaster reconstruction process relies on ad hoc laws and is led by regional and district governance structures. Moreover, because of various political as well as social reasons, a kind of distrust is built between the government and the people, and also between donor and the government. This leads into confrontation between the stakeholders, thus reconstruction/ rehabilitation plan cannot implement properly.

\subsubsection{No Local Government}

Although government of Nepal has set up powerful reconstruction authority to act regarding the 
post disaster reconstruction; inefficiency of local government, lack of co-ordination amongst different actors involved and lack of specific set of guidelines in post disaster condition has weakened the institutional setup of reconstruction process. One of the major challenges faced in the reconstruction process of Nepal is absence of elected local government ${ }^{2}$. For almost two decades, state appointed bureaucrats are leading the local level development works and all other development agendas. The last local election was held back in 1997 and the bureaucrats had been managed the local government. As a good sign, the government has successfully conducted election of newly structured local government in most part of Nepal including all the earthquake devastated area. It is believed that newly elected local government will speed up the reconstruction process. Lack of local government in local level was reflected in the major pre-disaster and postdisaster event, where it took months to reach the affected region and still no acceptable data is settled $^{1}$. Inefficiency of local governmental organizations has left the NRA and central government alone with the responsibility of restoration and reconstruction, causing problems to speed up the reconstruction. In addition, the absence of an elected local government, top down approach of governance has its own accountability deficit. After a disaster, local government needs to perform different set of tasks very quickly, and many of these must be performed simultaneously.

\subsubsection{Lack of Coordination}

Developing effective coordination within the NRA, between the NRA, local governments, and line agencies as well as between the NRA and other development organizations has been a continuing challenge in the process ${ }^{3}$. The three key structures within the NRA itself are the Executive Agency, the Advisory Board, and the Supervisory Board. The question of how these three bodies can interact efficiently so that the NRA as a whole can be effective has been a major issue ever since the NRA was established in early 2016. NRA's coordination with local governments has so far been rather weak. Initially, local governments expected that the NRA would help them implement local priorities. Disaster response was reflected on its 'unpreparedness', where there were long delays, bottlenecks, and a waste of relief assistance provided generously by people in all parts of the country. The engagement of many institutional actors - several ministries, I/NGO, districts, municipalities and VDCs - particularly in the reconstruction process, meant huge coordination difficulties. The involvement of such a wide range of national and local actors in the aftermath of a large disaster may not be surprising, but it is important to focus on the political nature of some of the reasons for such coordination problems.

\subsubsection{Performance of I/NGO}

One of the major reasons behind the ineffectiveness of the provision of humanitarian aid into reconstruction after Nepal earthquake is that much of the money did not directly reach victim, where much of it went on salaries, accommodation and transport for the I/NGO workers themselves. Nepal Red Cross Society has already spent US\$ 2.5 Billion in earthquake devastated districts ${ }^{4}$. However, noticeable results in reconstruction of physical structures and livelihoods of the victims have not seen yet. Nepal Red Cross Society is just an example; hundreds of similar I/NGOs are working on devastated area and spending billions of dollars. INGOs have been sharply criticized for failing to

2 "Local elections must to speed up reconstruction work, say experts" The Himalaya Times National Daily, Published on June 14, 2016

3 "Challenges in reconstruction" by Keshab Sharma, Nagarik National Daily, Published on Sep 16, 2015

4 "Progress .01 percent only" Nepal National Weekly, Published on November 13, 2016 
deliver effective humanitarian aid after the earthquake in Nepal as well. In addition to that, single window policy of NRA on NGO's involvement has controlled unnecessary flow of money but it has equally discouraged some genuine donors with its bureaucratic hassles. Unnecessary control of NGOs involvement in shelter has dispirited some genuine NGOs who already have networks of local groups, which could be effectively used in resourceful reconstruction process. Important to note, many I/NGOs are focusing on the areas having good access of road and other facilities such as bank, internet, hotel etc., which often ignores the larger section of marginalized group hindering the basic objectives of reconstruction.

\subsubsection{Bureaucratic Burdens}

On the other instance, we've seen inefficiency of NRA in its own institutional setup as well because of its bureaucratic egoism and political interventions. The government erred in not prioritizing adequate staffing of NRA. The politicization of the bureaucracy has weakened state authority to such a degree that it is now the tail that wags the dog. The irony here is that the majority of the civil servants are affiliated with the ruling party. There is also distrust that the NRA is being used as recruiting ground for the faithful, including those who are active members of intra-party 'professional' departments and allied NGOs. Bureaucracy has been trying to deal with the situation in a regular bureaucratic manner 5 .

\subsubsection{Corruption and Vested Interest}

With the scale of reconstruction to conduct and amount of budget involved in the process, reconstruction projects are prone to fall prey to fraud and corruption resulting in huge losses of project funding $[4,19]$. Problems with corruption and vested interests have been a major problem in big project and regular development activities in Nepal. One finds difficulty in pointing single project in Nepal that has been completed with design time and budget. Prolongation of the process and its limited control mechanisms allowed both local and national politicians to use it for personal gain. Kuntoro Mangkusubroto, the head of the reconstruction of Aceh in Indonesia after the 2004 tsunami presciently warned when he visited Nepal on 2015 that the three enemies of reconstruction were politics, bureaucracy and corruption, where Nepal seems to be unwittingly falling into these exact traps ${ }^{6}$.

\subsubsection{NRA Spending}

Weak governance in terms of efficiency and effectiveness is clearly reflected in the expenditure of reconstruction process. Nepal has a long record of struggling to meet government expenditure targets even without the additional post-disaster pressures $^{7}$, for instance; it managed to spend only three-quarters of the capital expenditure budget for roads, dams and other infrastructures in 2015/16. As at September 2016, spending by the NRA has lagged well behind budget. Under expenditure of this kind has led to widespread dissatisfaction among local people. The inability of the NRA to achieve its reconstruction target is reflected in the planned budget for NRA operations. The NRA has spent about 21 billion rupees for reconstruction so far against the budgetary allocation

5 "Nepal Earthquake: Bureaucracy continues to hinder relief and reconstruction" Asian Correspondent, Published on April 25, 2016

6 "Resuscitating Reconstruction" by Govind R. Pokharel and Swarnim Wagle, Republica National Daily, Published on June 15, 2016

7 "Reconstruction challenges become clear" The Economist Group, June 29, 2015 
of 91 billion rupees for the 2015-2016 fiscal year, the bulk of which reflected underspending in the areas of housing, infrastructure, and land use coordination..$^{8}$ One widely mentioned reason for spending delays was said to be the Nepal government's commitment to careful details and accurate household damage survey in affected district. As committed to donor agencies, NRA has finished the survey of household in affected districts including Kathmandu Valley damaged by earthquake for the second time. This explanation, however, was not well-received at the local level. Second, this continuing under expenditure naturally begs the question of whether the NRA will be able to execute planned budgets into the future. A German MP, Dagmar Wöhrl visited Nepal in March 2016, pointed out that "spending merely 13 per cent of foreign support is not simply enough"

\subsubsection{Lack of Experience}

Another annoyance troubling the reconstruction team lies in the lack of reconstruction experiences or preparedness. Although Nepal is a country accompanying many natural disasters, and even though the NRA team is claiming that the reconstruction process is the task, full of passion and commitment, lacking of reconstruction planning experiences is an obvious weakness. At the first period of the reconstruction planning work, many planners were confounded at what to do. And the first plans were just like just ordinary plans, ignoring or at least not fully considering the special aspects of reconstruction. Until the catastrophe of the 2015 Gorkha Nepal earthquake, there has been no special legislation on counter-natural disaster response system in the past. It is obviously a failure of the disaster response system. For another instance, more than 1500 engineers and architects have been employed by the government and deployed in disaster affected districts and VDCs. But the task of the engineers is not well defined which completely aids to the loss of resources and delays in reconstruction.

\subsubsection{Techno-legal Regime}

The most crucial factor in reducing a community's risk from an earthquake is the adoption and enforcement of up-to-date building codes and land use planning. To survive and remain resilient, communities must strengthen their core infrastructure and critical facilities so that these can withstand an earthquake or other disaster and continue to provide essential services. Government of Nepal has decided to implement the Nepal building code in Kathmandu Valley in 2002. However, nearly 90 percent of structures in Kathmandu have not received the "construction conclusion" certificate, only because their homes do not meet building codes of Nepal. Sharma et al. [15] and Sharma and Deng [14] also concluded that a majority of the damaged buildings were not designed or constructed properly in accordance with national building codes of Nepal. There does not exist an effective building monitoring and site enforcement mechanism for implementing and enforcing the building code - even in the Kathmandu Valley and municipalities, let alone in the rural ones. Land use planning after a mega earthquake can be an instrumental to reduce future seismic risk which could be a significant part of reconstruction. Reconstruction in large scale without land use planning will not be sustainable and long-lasting. NRA has still got to work to ensure that those places are safe and resilient to future disaster risks while talking about reconstruction. The government has formulated a land use policy but the haphazard construction and development

8 "NRA to get budget of around NRs 150bn next fiscal year" The Himalayan Times, Published April 14, 2016

9 "Pace of post-quake reconstruction too slow, say German MPs" The Himalayan Times, Published March 27,2016 
works has put a big question over its effective implementation ${ }^{10}$.

\subsubsection{Public Participation}

Often while planning or doing engineering works, most of the technical jargons overshadow the real demand of people affected. It is often ignored or forgotten that the affected people are center of this whole reconstruction process. Especially when the institutional set up of NRA is broadly the elaborated concept of top-down approach. The reconstruction framework, which basically overlooks the importance of participation and integration of cultural and social assets in reconstruction process ${ }^{11}$, is doomed to fail. In most of the reconstruction process, cognitive mapping and social integration of planning have proved to be very efficient. Most of the plans have been performed following a top-down paternalistic approach, which has led to dissatisfaction among the people and lacks the sense of ownership regardless of several governmental and nongovernmental efforts. Ignoring on local level integration of governance and politicization of the process through national, regional, and local structures has troubled the reconstruction in many ways. However, it is important to consider this challenge also from different perspective as for local actors to participate effectively in post-disaster reconstruction environments; they need to be aware and equipped with certain capacities and resources, which will enhance their understanding for further years in disaster risk management ${ }^{12}$. Jigyasu [5] and Marahatta [10] have explicitly focused on capitalization of community based knowledge and their implication in pre-disaster and post disaster reconstruction process.

\subsubsection{Lack of Comprehensive Information}

Comprehensive planning is an integrated approach for bringing different planning that is done within a town from different actors. In simplest example, it keeps everything in order beforehand and in future [7]. One of the obstacles impeding the process of rehabilitation is the lack of comprehensive information about the demographics of the people and the number of households of each district. The lack of this information was significantly noted during the rescue and distribution of relief material and fund. Immediately after the disaster, a preliminary assessment often referred as rapid assessment or situation assessment was conducted to obtain an early but full assessment of the geographical extent of damage, the number, categories, location, and circumstances of the disaster-affected population took months to acknowledge, even those statics are not widely accepted. Due to lack of statistical system, some people residing as a temporary resident could not get any relief materials and fund. They will be deprived from the special fund or loan provided by the government to build earthquake resistant house and many other privileges for earthquake victims. NRA is still struggling to distribute second installment of grants even two years after the devastating quakes and detailed damage assessment of Kathmandu Valley is yet to be completed.

\subsubsection{Poverty, Inequality and Unemployment}

Existing social problems such as poverty, inequality, and unemployment before earthquake have increased vulnerability of people and hindered people's interest to accelerate the reconstruction, especially to build seismic resistant residential building. A larger proportion of the population is

10 "Geological study before rebuilding" by Pragati Shahi, Kathmandu Post National Daily, Published on February 24, 2016

11 "Equitable reconstruction" by Gyan Basnet, The Himalayan Times, Published on September 17, 2015

12 "When will Nepal rise from the rubble" by K. Sharma, Annapurna Post, Published on Nov 16, 2016 
economically disadvantaged. They do not have access to or in most cases cannot afford modern materials such as cement and steel to build earthquake resistant building as per the prevailent design features available. Furthermore, the cost is exacerbated by transport costs in those difficult terrains. People who have physical, social and personal vulnerabilities has suffered the most and are finding it difficult to get back to normal life. Dalits, single women, children, and people with disabilities are among greatly disadvantaged group. This leads to intensification of social confusion and delays rehabilitation. Improper and unequal distribution of resources is another key factor hindering inclusive reconstruction. In many cases, improper management has resulted wastage of resources leading to more difficulties among the survivors.

\subsubsection{Lack of Public Awareness}

Lack of public awareness is another subcategory causing problems for people at disaster time and even during the process of getting back to normal life and reconstruction. Lack of advanced knowledge and skills to respond and recover from a disaster and current level of education of public made them unable to play active role in the process. Although the area is highly seismically active, there is no frequent large earthquake in the area; there is a severe lack of awareness at all levels of society. Before the great earthquake, information dissemination or awareness has never been the priority of government apart from some NGOs carrying out the task.

\subsubsection{Negligence of Local Culture}

Government of Nepal has proposed 17 different building models for residential housing to be constructed as a reconstruction after earthquake. Out of 800,000 collapsed houses, more than 80 $\%$ houses were traditional houses built up with mud mortar. Government has proposed only two models one is stone masonry with mud mortar and the second is brick masonry with mud mortar. Those houses are really small in size, even not enough for a nuclear family. These model houses do not represent house of any caste or religious people. ${ }^{13}$ Rest of 15 models are either stone or brick masonry in cement mortar with reinforced bar. Couples of houses designed in the center do not meet the needs of people in earthquake stricken areas. So, people do hesitate to adopt the government designed houses. Government has not proposed yet the model for cattle shade (barn) which is equally important as houses in term of lively hood of the people live in village. Husbandry and agriculture have been also neglected. The inability to consider the local cultural need has led to other problems in reconstruction. Negligence of special requirements in rural houses was one the main aspects of reconstruction that lead to dissatisfaction and uncertainty in people's lives.

\subsubsection{Accessibility}

The earthquake area is spread over 10,000 square kilometers and is mostly in very rugged, high altitude, that is remote and with low accessibility. It is so spread out that, in some cases, it takes over 1 day by road to travel from one end of the affected district to the other. To reach many of the villages at high altitude, it takes another day from the nearest road. Many of the areas are totally cut off during monsoon due to high flow in river. The terrain makes transporting construction materials an impossible task in most of the area $^{14}$.

13 "Go local" By Keshab Sharma, Republica National Daily, Published on April 19, 2016

14 "Reconstruction work hindered by lack of roads" The Himalayan Times, Published on Nov 2, 2016 


\subsubsection{Manpower Shortage}

About 2.2 million Nepalese youths are working in foreign countries (excluding India) as migrant workers. It was predicted that the reconstruction effort would require some 10,000-skilled manpower that included engineers, foremen, masons, and carpenters - and another 40,000 semiskilled/ unskilled workers ${ }^{15}$. Developing manpower on this scale is in itself a mammoth task. National Planning Commission's damage and needs assessment in 2015 estimated that only 20\% of the needs of human resources could be met within Nepal's existing resources. Therefore, the phenomenon of migrant labor and the need to train and inform them was identified from a very early stage. However, unfortunately NRA has not proposed a rigid plan to train such a huge number of manpower required to accelerate the reconstruction. Many people can build their houses without financial support from the government and also are willing to build the house as soon as possible but are facing lack of manpower and do not know how to construct earthquake resistant building.

\subsubsection{Knowledge Gap and Building Construction}

The construction workforce, in general, lacked knowledge of earthquake-resistant technology because it has never been considered as an integral part of general engineering education in Nepal. Moreover, construction artisans in the area are not formally trained. Their skills are passed down from generation to generation, or learnt from other masters. Of course, a small number of craftsmen who have worked in the Gulf States or in urban areas have better experience in steel fixing, concrete, etc. Without formal training, newer techniques for use with modern materials are not being introduced to craftsman and technicians. Technology dissemination is considered complete once it reaches the professional engineering community and midlevel technicians. The building construction mechanism is mostly vernacular, non-formal, incremental in nature, and dictated by local availability of construction materials. The engineering community does not know much about these construction types. Furthermore, the academic institutions appear to be more apathetic towards both non-engineered materials and traditional technologies which is quite injustice to cultural inheritance of vernacular technology.

\subsubsection{Loss of Livelihood}

Hundreds of thousands of people in Nepal depend on agriculture to make a living and lost the main source of their livelihoods during the devastating earthquakes and their aftershocks. Without an income from crop cultivation and animal farming, people's ability to feed their families has been hampered. Various organizations and government entities have distributed shelter kits, cooking kits, and grain bags to farming household's right after the disaster as relief, enabling them to salvage stocks of food and to safely store rice, maize, and other types of crops. ${ }^{16}$ No attention has been primarily paid to livelihood such as agriculture, husbandry, employment and other social issues by government and I/NGOs. This has led to intensification of social uncertainty and confusion in the earthquake affected area. The affected people are also concentrated on reconstruction and do not attend to the other aspect of recovery.

15 "EARTHQUAKE Mission Reconstruction" by Keshab Poudel, Spotlight News Magazine, Published on May 08, 2015

16 “Go local" by Keshab Sharma, Republica National Daily, Published on April 19, 2016 


\subsubsection{Rehabilitation and Retrofitting}

Many existing structures including residential buildings located in devastated area survived the 2015 Gorkha earthquake but are inadequate based on current seismic design codes. Massive demolition and replacement of these vulnerable buildings is neither affordable nor feasible due to historical, cultural, social, and economic constraints. Retrofitting is a very relevant technique to restore as well as strengthen the existing undamaged buildings which are otherwise weak against earthquake likely to occur in future. Though, there is both financial and technical support for new construction and NRA has already proposed some model buildings for new construction, there is no support or guidance for retrofit of the large number of partially damaged houses. Recently UNDP has provided some retrofitting guidelines to the government which is under the process of government endorsement, but there lacks some serious level of awareness in general public about strengthening of built structure. The retrofitting program can't be neglected because carrying on such program is essential for all economic, political and social reasons. As entire Nepal is highly vulnerable to earthquake disaster, the knowledge and resources developed for retrofitting during the reconstruction in devastated area can/should be disseminated to the other parts of Nepal which is likely to hit by big earthquake in future.

\section{Conclusion}

With different interactions and analysis of the status quo, authors are convinced with the persistent conception of politics as the root of the problem, as all the problems tend to converse to the common point. It is quite understandable in the period of political transition, different institutions and systems are not in order of good performance, especially in case of countries like Nepal which is struggling with stable ruling system for seven decades and more. Twenty factors identified and briefly explained in this paper, presents the comprehensive idea about the reconstruction process as whole and points out the gaps, we need to address. These wide range of topics cover different issues as NRA's spending, coordination and commitments gaps amongst stakeholders, local government and governance, lack of public awareness, socio-economic status of people with poverty, inequality, discrimination and unemployment, lack of comprehensive information, incapacity of I/NGO, timely reconstruction and lack of local participation and ownership. Such issues have also featured some crosscutting topics like difficult topography, phony political commitments, manpower shortage, lack of experience, negligence of local culture, manpower shortage, knowledge gap in building construction technology and materials, loss of livelihood, no plan for retrofitting and rehabilitation. Bureaucratic burdens, vested interests and corruption, and concentration on distribution of subsidy for house and overlooking of rehabilitation are incorporated in different topics of issues.

With all those gloomy pictures of problems identified in this paper, there are still some rays of hope: election of local government on May 14, implementation of constitution, increasing number of trained manpower, engineers from NRA, new powerful and comprehensive institutions and regulations being forwarded by the government in the process and many more. But the most importantly, one can only expect the well-intended coordination of different actors and stakeholders to work hand in hand within the limitation but with optimum utilization of available resources, for effective and efficient reconstruction.

Acknowledgement: The authors appreciate the discussions with local political leaders and Engineers from NRA, DUDBC and different I/NGOs. They are also sincerely acknowledged for their kind support during the collection of the questionnaire survey. 


\section{References}

[1] Balachandran BR (2005), The reconstruction of Bhuj case study: integration of disaster mitigation into planning and financing urban infrastructure after an earthquake. The World Bank.

[2] Doocy S, Daniels A, Packer C, Dick A and Kirsch TD (2013), The Human Impact of Earthquakes: a Historical Review of Events 1980-2009 and Systematic Literature Review. PLOS Currents Disasters.

[3] Gharaati M and Davidson C (2008), Who knows best? An overview of reconstruction after the earthquake in Bam, Iran. The 4th International i-Rec Conference, University of Canterbury, Christchurch, New Zealand.

[4] Hidayat B and Egbu, C (2010), A Literature Review of The Role of Project Management in PostDisaster Reconstruction. In C Egbu (Ed.), Proc. 26th Annual ARCOM Conference, 6-8 September 2010, 1269-1278. Association of Researchers in Construction Management.

[5] Jigyasu R (2002), Reducing disaster vulnerability through local knowledge and capacity' PhD Thesis, Norwegian University of Science and Technology.

[6] Jones S, Oven KJ, Manyena B and Aryal K (2014), Governance struggles and policy processes in disaster risk reduction: A case study from Nepal. Geoforum, 57 : 78-90.

[7] KC A (2015), Role of Good Urban Governance for Comprehensive Planning in Nepal: Actors and Participation. MSc Thesis, Tribhuwan University, Department of Architecture and Urban Planning.

[8] KC A, Sharma K and Pokharel B (2017), Performance of heritage structure in Kathmandu Valley during 2015 Gorkha Nepal earthquake, Journal of Earthquake Engineering (in press).

[9] Kwok TC (2016), Continued Challenges in Rebuilding Haiti, E-International Relation (published on March 11).

[10] Marahattha PS (2013), Community-based Earthquake Vulnerability Reduction in Traditional Settlements of Kathmandu Valley' PhD Thesis, Tribhuwan University.

[11] Mumtaz H, Habib Mughal S, Stephenson M, Bothara JK (2008), The challenges of reconstruction after the October 2005 Kashmir earthquake. The NZSEE Annual Conference, New Zealand.

[12] Phalkey R, Reinhardt JD and Marx M (2011), Injury epidemiology after the 2001 Gujarat earthquake in India: a retrospective analysis of injuries treated at a rural hospital in the Kutch district immediately after the disaster, Glob Health Action, $4: 7196$.

[13] Post Disaster Needs Assessment (PDNA) Nepal earthquake 2015: post disaster needs assessment, published by government of Nepal www.npc.gov.np (2015).

[14] Sharma K and Deng L (2017), Reconnaissance report on geotechnical engineering aspect of the 2015 Gorkha, Nepal, earthquake. Journal of Earthquake Engineering: 1-26.

[15] Sharma K, Deng L and Cruz-Noguez C (2016), Field investigation on the performance of building structures during the April 25, 2015, Gorkha earthquake in Nepal. Engineering Structures, $121: 61-74$.

[16] Sharma K, KC A and Pokharel B (2017), Challenges for reconstruction after $M_{w} 7.8$ Gorkha earthquake: a study on devastated area of Nepal. International Journal of Disaster Risk Reduction (in review).

[17] Soelaksono A (2009), NGO and Donor Coordination to Speeds up Reconstruction and Avoid NGO Competition. The 4th Annual International Workshop \& Expo on Sumatra Tsunami and Recovery in Banda Aceh, Banda Aceh.

[18] Uyangoda J (2005), Post-Tsunami Recovery in Sri Lanka, Polity, $2: 3$.

[19] Wardak ZS, Coffey V, and Trigunarsyah B (2012), Rebuilding Housing after a Disaster : Factors for Failure. In 8th Annual International Conference of the International Institute for Infrastructure, Renewal and Reconstruction (IIIRR): 292-300. 